Психология. Журнал Высшей школы экономики.

2010. T. 7, № 3. С. $72-80$.

\title{
СРАВНИТЕЛЬНОЕ ИССЛЕДОВАНИЕ ИНДИВИДУАЛЬНОСТИ В РАЗЛИЧНЫХ ИЗМЕРИТЕЛЬНЫХ ПРОЦЕДУРАХ
}

\author{
М.Д. МОРОВ
}

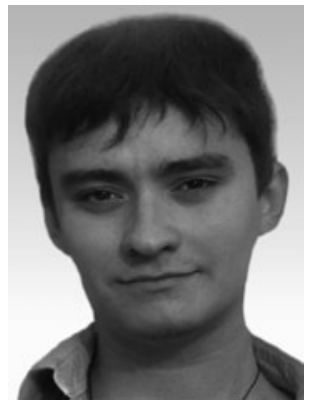

Моров Михаил Дмитриевич - аспирант ГУ-ВШЭ. Сфера интересов - клиническая психология, психологическое консультирование, методология психологии. Контакты: md_moroff@mail.ru

В настоящий момент времени существуют различные измерительные процедуры, позволяющие описать индивидуальность. В статье делается попытка осветить проблему, насколько индивидуальность конкретного человека идентична в различных измерительных прочедурах. Дается ответ на вопрос, возможно ли в психологических исследованиях рассматривать как эквивалентные результаты, полученные с помощью методик, которые имеют разное теоретическое основание.

Ключевые слова: индивидуальность, личность, личностное качество, измерительные процедуры.

Для изучения индивидуальности используются различные тесты. В некоторых исследованиях эти тесты рассматриваются как эквивалентные. Но обращение к теоретическим основаниям различных методик позволяет высказать сомнения в таком подходе.

Встает проблема, насколько индивидуальность конкретного человека идентична в различных системах измерительных процедур. Для того чтобы рассмотреть индивидуальность в системе измерительных процедур, обратимся к методологическому принципу «полноты описания индивидуальности» (Штерн, 1998; Шадриков, 2009a). Данный принцип предполагает регистрацию в психограмме всей полноты признаков, доступных исследователю. В такой психографической схеме 
качества организуются в иерархическую систему, выделяются базовые, ведущие и второстепенные качества. Все качества обобщаются, группируются, выделяются те, которые играют интегрирующую роль. Полученные качества анализируются относительно их веса и степени корреляции с успешностью деятельности. Здесь возникает проблема подбора генерального перечня конкретных измерительных процедур. Связано это с тем, что все известные на сегодняшний день методы комплексной диагностики личности, индивидуальности, характера или темперамента создавались в рамках конкретных теорий, не всегда согласующихся между собой (Акимова, 2005). Например, опросник ММРI создавался в рамках конкретной типологии личности, основанной на клиническом подходе, т. е. при создании опросника в выборку входили как здоровые испытуемые, так и с психическими расстройствами. Личностные качества, выявлявшиеся данной методикой у той или иной группы испытуемых, получали названия соответствующего симптомокомплекса, таким образом формировались личностные типы (Соломин, 2003). Профиль личности в данном случае отражает степень близости конкретной личности к тому или иному личностному типу.

Если взять 16-факторный опросник Кеттелла, который создавался в рамках теории личностных черт, то там принцип формирования был иным. Бралась выборка различных людей, и результаты проведения опросника подвергались факторному анализу. Таким образом, принцип построения личностного профиля был отличным от того, который использовался при построении МMPI (Рукавишников, Соколова, 2006).

Мы провели теоретический анализ содержания шкал и факторов различных личностных методик, которые включали 16-факторный личностный опросник Кеттелла, Характерологический опросник Леонгарда, Личностный опросник Айзенка и опросник Мини-мульт (сокращенная и упрощенная версия MMPI), в результате мы выявили те шкалы и факторы, которые имеют в своем содержании одни и те же личностные качества. Исследование должно было дать ответ на вопрос, совпадает ли диагноз личностных качеств по шкалам и факторам, имеющим в своем содержании одинаковые личностные качества, у одного и того же человека по различным тестовым методикам. Важность ответа на данный вопрос обусловлена тем, что в современных исследованиях личностные методики используются как взаимозаменяемые. Результаты по данным методикам часто рассматриваются как эквивалентные, и ответ на поставленный вопрос может разъяснить, является ли идентичной индивидуальность, описанная в различных измерительных процедурах.

С целью ответа на поставленный вопрос мы провели свое исследование, которое осуществилось на базе Государственного университета Высшей школы экономики. В исследовании приняли участие 72 человека в возрасте от 18 до 22 лет, являющиеся студентами различных факультетов. Испытуемым было предложено 4 опросника (16-факторный личностный опросник Кеттелла, опросник Мини-мульт, Характерологический 
опросник Леонгарда и Личностный опросник Айзенка). Результаты исследования были подвергнуты статистическому анализу методом ранговой корреляции Спирмена с исполь- зованием статистического пакета обработки данных SPSS Statistics 17.0. Результаты корреляционного анализа представлены в таблицах 1 , 2,3 .

Корреляции, полученные между факторами 16-факторного личностного опросника Кеттелла и шкалами опросника Мини-мульт

(представлены значимые корреляции с уровнем значимости $p<0.001$ )

\begin{tabular}{|l|c|c|c|c|c|c|c|c|}
\hline & \multicolumn{7}{|c|}{ Мини-мульт } \\
\hline Опросник Кеттелла & Ип & Деп & Ист & Пп & Пар & Па & Шиз & Гм \\
\hline Шкала A & & & & & & & 0.617 & 0.69 \\
\hline Шкала B & & & & & & & & \\
\hline Шкала C & & & & -0.71 & & -0.74 & & \\
\hline Шкала E & & & & & & & & \\
\hline Шкала F & & & & & -0.69 & & & 0.77 \\
\hline Шкала G & & & & 0.86 & & & & \\
\hline Шкала H & & & & & & & & \\
\hline Шкала I & & & & & & & & \\
\hline Шкала L & & & & & & & & \\
\hline Шкала M & & & & & & & & \\
\hline Шкала N & & & & & & & & -0.69 \\
\hline Шкала O & & 0.66 & & 0.71 & & 0.95 & & \\
\hline Шкала Q1 & & & & & & & & \\
\hline Шкала Q2 & & & & & & & & \\
\hline Шкала Q3 & & & & & & & & \\
\hline Шкала Q4 & & & & & & & & \\
\hline
\end{tabular}

Примечание. Здесь и далее используются следующие обозначения шкал. Опросник Мини-мульт: Ип - Шкала ипохондрии, Деп - Шкала депрессии, Ист - Шкала истерии, Пп - Шкала психопатии, Пар - Шкала паранойальности, Па - Шкала психастении, Шиз - Шкала шизоидности, Гм - Шкала гипомании. Опросник Кеттелла: Шкала А - Шизотимия/Аффектотимия, Шкала В - Низкий интеллект/высокий интеллект, Шкала С - Слабость Я/сила Я, Шкала Е - Конформность/доминантность, Шкала F - Сдержанность/Экспрессивность, Шкала $\mathrm{G}$ - Низкое супер-Эго/высокое супер-Эго, Шкала Н - Тректия/Пармия, Шкала I - Харрия/Премсия, Шкала L - Алаксия/Протенсия, Шкала M - Праксерния/Аутия, Шкала $\mathrm{N}$ - Прямолинейность/ Дипломатичность, Шкала О - Гипертимия/Гипотимия, Шкала Q1 - Консерватизм/Радикализм, Шкала Q2 - Зависимость от группы/Самодостаточность, Шкала Q3 - Низкое самомнение/Высокое самомнение, Шкала Q4 - Низкая Эго-напряженность/Высокая Эго-напряженность. 
Таблица 2

Корреляции, полученные между факторами 16-факторного личностного опросника Кеттелла и шкалами Характерологического опросника Леонгарда и Личностного опросника Айзенка (представлены значимые корреляции с уровнем значимости $p<0.001$ )

\begin{tabular}{|c|c|c|c|c|c|c|c|c|c|c|c|c|c|}
\hline & \multicolumn{10}{|c|}{ Опросник Леонгарда } & \multicolumn{3}{|c|}{$\begin{array}{c}\text { Опросник } \\
\text { Айзенка }\end{array}$} \\
\hline $\begin{array}{l}\text { Опросник } \\
\text { Кеттелла }\end{array}$ & Гт & 3 & Эм & Пед & $\mathrm{Tp}$ & Ц & Дем & Воз & Дис & Экз & $\Pi$ & $Э$ & $\mathrm{H}$ \\
\hline \multicolumn{14}{|l|}{ Шкала А } \\
\hline Шкала В & & & & & & 0.78 & & & & & & & 0.65 \\
\hline Шкала C & & & & & -0.79 & & & & & & & & \\
\hline \multicolumn{14}{|l|}{ Шкала Е } \\
\hline \multicolumn{14}{|l|}{ Шкала F } \\
\hline Шкала G & & & & & & & & 0.89 & & & 0.68 & & \\
\hline Шкала Н & -0.60 & & & & & & & & & & & & \\
\hline Шкала I & 0.77 & & & & & & & -0.69 & & & & & \\
\hline Шкала L & & & & & & & & & & -0.65 & & & \\
\hline Шкала М & -0.63 & & & & & & & & & & & & \\
\hline Шкала N & & & & & & & & & & & & -0.79 & \\
\hline Шкала O & & 0.82 & & 0.73 & & & & & & & & & 0.71 \\
\hline Шкала Q1 & & & & & & & 0.72 & 0.7 & & & & & \\
\hline \multicolumn{14}{|l|}{ Шкала Q2 } \\
\hline Шкала Q3 & 0.77 & & 0.71 & & & & & & & & & 0.66 & \\
\hline Шкала Q4 & & 0.69 & & 0.75 & & 0.63 & & & & & & & 0.89 \\
\hline
\end{tabular}

Примечание. Здесь и далее используются следующие обозначения шкал. Опросник Леонгарда: Гт - Гипертимность, 3 - Застревание, Эм - Эмотивность, Пед - Педантичность, Тр - Тревожность, Ц - Циклотимия, Дем - Демонстративность, Воз - Возбудимость, Дис - Дистимия, Экз Экзальтированность. Опросник Айзенка: П - Психотизм, Э - Экстраверсия, Н - Нейротизм. 
Корреляции, полученные между шкалами Характерологического опросника Леонгарда и шкалами опросника Мини-мульт и Личностного опросника Айзенка (представлены значимые корреляции с уровнем значимости $p<0.001)$

\begin{tabular}{|l|c|c|c|c|c|c|c|c|c|c|c|}
\hline $\begin{array}{l}\text { Опросник } \\
\text { Леонгарда }\end{array}$ & \multicolumn{7}{|c|}{ Мини-мульт } & \multicolumn{3}{|c|}{$\begin{array}{c}\text { Опросник } \\
\text { Айзенка }\end{array}$} \\
\hline & Ип & Деп & Ист & Пп & Пар & Па & Шиз & Гм & П & Э & Н \\
\hline Гт & & & & & & & & & & & \\
\hline 3 & & & 0.66 & 0.73 & & 0.81 & 0.66 & & & & 0.76 \\
\hline Эм & 0.73 & & & & & & 0.84 & & & & \\
\hline Пед & 0.6 & & & 0.68 & & 0.74 & 0.74 & & & & 0.77 \\
\hline Тр & & & 0.73 & & & 0.89 & & & & & 0.61 \\
\hline Ц & & & & & 0.65 & & & & & & 0.75 \\
\hline Дем & & & & & & & & & & & \\
\hline Воз & & & & 0.79 & & & & & & & \\
\hline Дис & & 0.83 & 0.69 & & 0.89 & & & & & & \\
\hline Экз & 0.65 & & & & & & & & & & \\
\hline
\end{tabular}

В результате статистической обработки было получено 57 значимых корреляций с уровнем значимости $p<0.001$ (таблицы 1-3). Все корреляции можно разделить на три группы. В первую группу вошли корреляции, которые наблюдались между шкалами, имеющими в своем содержании одинаковый или сходный набор личностных качеств, например, корреляция между шкалой Гипомания опросника Мини-мульт и полюсом Аффектотимия фактора «A» 16-факторного личностного опросника Кеттелла. Данные шкалы имеют в своем содержании такие качества, как Активность, Энергичность, Преобладание веселого настроения, Общительность, Открытость и др. Вторую группу составляют корреляции, касающиеся шкал и факторов, не имеющих в своем со- держании одинаковых или сходных личностных качеств, но и не имеющих в своем содержании противоположных качеств, например, корреляция между шкалой Эмотивность Характерологического опросника Леонгарда и шкалой Шизоидность опросника Мини-мульт. Определяющими качествами, входящими в шкалу Эмотивность, является подверженность частым переменам настроения, повышенная чувствительность, чрезмерная зависимость поведения от настроения, в то время как основными качествами шкалы Шизоидность являются замкнутость, узость интересов, причудливость и парадоксальность мышления, эмоций и поведения. Качества, входящие в данные шкалы, могут наблюдаться у одного и того же человека, не являются дублирующими либо противоречащими 
друг другу. В третью группу вошли корреляции, наблюдавшиеся между шкалами и факторами, имеющими в своем содержании явно противоположные личностные качества, например, корреляция между шкалой Шизоидность опросника Мини-мульт и полюсом Аффектотимия фактора «А» опросника Кеттелла.

Стоит отметить, что между многими шкалами и факторами, которые в результате теоретического анализа должны давать согласующиеся результаты, корреляций не наблюдается, например, шкала Истерия опросника Мини-мульт и шкала Демонстративность Характерологического опросника Леонгарда имеют в своем содержании такие личностные качества, как демонстративность, склонность к привлечению внимания других людей, наигранность, но корреляции между данными шкалами не наблюдается.

Исходя из теоретического основания методик, обозначенных в исследовании, многие качества характеризуются как идентичные, но, согласно полученным экспериментальным данным, видно, что в некоторых случаях данные качества на совпадают. В результате мы получаем два различных профиля личности для одного и того же человека.

Чтобы понять, почему результаты между методиками, исследующими одну и ту же личность и описывающими ее одним и тем же набором предикатов, не согласуются между собой, необходимо обратиться к содержанию стимульного материала данных методик.

Опросник Кеттелла, как мы уже говорили, создавался методом факторизации результатов. Огромное число вопросов, моделирующих различные жизненные ситуации, в которых должны проявляться те или иные личностные качества, было сгруппировано в факторы, получившие названия различных симптомокомплексов (Рукавишников, Соколова, 2006). Если мы обратимся к конкретным вопросам, составляющим какой-либо фактор, то мы увидим, что не все ситуации, моделируемые данными вопросами, вызывают проявление тех качеств, которые прописаны в содержании фактора, а также увидим, что многие ситуации, представленные в вопросах, затрагивают более широкий спектр качеств, чем заявленный в содержании фактора. Для примера рассмотрим корреляцию между фактором «А» опросника Кеттелла и шкалой Шизоидность опросника Мини-мульт (таблица 1). Корреляция наблюдается между полюсом Аффектотимия фактора «А» и высоким показателем по шкале Шизоидность. Рассмотрим данные шкалы более подробно. Фактор «А» является биполярным, т. е. низкие результаты по данному фактору свидетельствуют о наличии одного симптомокомплекса, в данном случае это шизотимия, а высокие результаты говорят о наличие у испытуемого другого симптомокомплекса, в данном случае аффектотимии. Если говорить коротко, аффектотимия описывается через открытость другим людям и стремление работать совместно. Шизотимия, напротив, характеризует склонность человека к замкнутости и отстраненности. Возьмем для примера один из вопросов, входящих в данный фактор: «При одинаковом рабочем времени и заработке вам было бы интереснее 
работать: а) плотником или поваром; б) не уверен; в) официантом в хорошем ресторане». В данном случае, если испытуемый выбирает ответы «не уверен» или «официантом в хорошем ресторане», это расценивается как склонность к аффектотимии, т. е. к общительности, открытости, доброте, внимательности к людям, готовности к сотрудничеству. Первым фактом, свидетельствующим о том, что данный вопрос затрагивает качества, не входящие в описание полюсов фактора «А», является то, что здесь участвуют социальные стереотипы профессий, представленных в вопросе. Например, повар может быть контактным, работающим в большом коллективе в ресторане, также и официант может работать в тихом заведении, тем более здесь указывается на то, что это официант хорошего ресторана, в котором не обязательно очень много посетителей. Также человеку может быть приятна работа с деревом. И он выберет профессию плотника, потому что ему нравится создавать что-то новое или просто приятен запах древесины. Второй факт, который показывает, что данный вопрос не отражает качеств, заявленных в содержании полюсов фактора, - ответ «не уверен» относится к аффектотимии. Если испытуемый выбирает данный ответ, это говорит о том, что либо вопрос ему не интересен, либо ему трудно принимать решения, либо ему трудно представить данные профессии, либо его привлекают все профессии, либо его не привлекает ни одна. Этот ответ никак не позволяет судить о степени общительности и открытости личности либо о других качествах, входящих в описа- ние аффектотимии. Учитывая то, что такой вопрос не единичен, мы получаем на выходе профиль личности, в большой степени неадекватно описывающий личность.

Рассмотрим опросник Минимульт, который является сокращенной версией MMPI и использует его типологию личности. Данная типология основывается на том, что у лиц с различной психической патологией наблюдаются определенные личностные качества. При том что принцип выделения типов личности здесь отличается от принципа формирования факторов в опроснике Кеттелла, набор личностных качеств, выявляемых опросником Мини-мульт, является тем же самым, что и в опроснике Кеттелла, а содержание полюсов некоторых факторов опросника Кеттелла практически дублирует содержание некоторых шкал опросника Мини-мульт.

Если мы рассмотрим вопросы, составляющие шкалы опросника Мини-мульт, то увидим, что бо́льшая их часть сводится к уточнению симптомов, возникающих при психической патологии (Соломин, 2003). Также многие вопросы моделируют ситуации, затрагивающие личностные качества, не свойственные той шкале, в которую включен вопрос. Например, возьмем шкалу Шизоидность, которая теоретически должна совпадать в своих результатах с полюсом шизотимии фактора «A» опросника Кеттелла. Шизоидность понимается как замкнутость, необщительность, узость интересов, несогласованность мыслительной и эмоциональной сфер. Вот пример вопроса, входящего в шкалу Шизоидность: «В детстве вы одно время 
совершали кражи». Если испытуемый отвечает на данный вопрос утвердительно, то это расценивается как склонность его к шизоидному типу. Стоит сказать, что кражи в детском возрасте свойственны не только лицам с шизоидностью, но и, например, с гипотимией или психопатией, согласно типологии личности MMPI (Соломин, 2003). Кражи, которые совершает ребенок, могут быть связаны не только с личностными факторами, но и с социально-экономическими, что также создает трудности для адекватной диагностики. Таким образом, личностный профиль, полученный в результате выполнения опросника Мини-мульт, в большой степени не отражает характеристик реальной личности.

Если взять Характерологический опросник Леонгарда и Личностный опросник Айзенка (Анастази, 1982; Леонгард, 2000), то мы увидим те же самые противоречия, заключающиеся в том, что не все вопросы, входящие в шкалы данных опросников, выявляют качества личности, представленные в описаниях данных шкал, и в том, что многие вопросы затрагивают такие личностные качества, которые не входят в описание симптомокомплексов, выявляемых с помощью них.

В Характерологическом опроснике Леонгарда большая часть вопросов ориентирована на самоанализ, например, «Общительны ли вы?» или «Предприимчивы ли вы?». Ответы на данные вопросы могут быть следствием представления человека о себе и не иметь отношения к его личностным качествам. Также многие вопросы не моделируют никаких ситуаций, требуя провести самоанализ.
В Личностном опроснике Айзенка многие вопросы затрагивают социальную активность личности, ее поведение в обществе, следование моральным нормам и правилам. Также есть вопросы, требующие самоанализа и не моделирующие жизненных ситуаций, что также искажает результаты опросника. Качества, исследуемые Личностным опросником Айзенка, не отличаются от качеств, исследуемых опросником Кеттелла, опросником Мини-мульт и опросником Леонгарда, но в силу того, что конкретные способы регистрации личностных качеств различны, возникает разность результатов этих методик.

Таким образом, как было показано, вопросы, относящиеся к тем или иным шкалам и факторам, затрагивают более широкий спектр личностных качеств и сферу интересов личности. Мы можем объяснить возникновение корреляций между теми шкалами, где их быть не должно. Такие корреляции, конечно, могут быть и случайными, но возможно и то, что две или более шкал различных опросников исследуют качества личности, не входящие в описания этих шкал, либо входящие только в описание одной из шкал, в результате чего возникает корреляция между шкалами и факторами, направленными на исследование различных личностных качеств.

Результаты по ряду шкал, имеющих идентичное содержание, совпадают, но некоторые шкалы с одинаковым содержанием дают разные результаты, кроме того, результаты иногда совпадают в шкалах, имеющих разное или противоположное 
содержание. Следовательно, необходимо осторожно относиться к описаниям индивидуальности, получен-

\section{Литература}

Акимова М.К. Психологическая диагностика: Учебное пособие. СПб.: Питер, 2005.

Анастази А. Психологическое тестирование. М.: Педагогика, 1982.

Леонгард $K$. Акцентуированные личности. Ростов-н/Д.: Феникс, 2000.

Рукавишников А.А., Соколова М.В. Факторный личностный опросник Кеттелла: Методическое руководство. СПб.: ИМАТОН, 2006.

Соломин И.Л. Личностный опросник MMPI: Методическое руководство. СПб.: ИМАТОН, 2003. ным в различных измерительных процедурах, а диагноз личности должен даваться в вероятностном ключе.

Шадриков В.Д. Психологическая характеристика нормального человека, или Познай самого себя. М.: Университетская книга; Логос, 2009а.

Шадриков В.Д. Психология индивидуальности: Новые модели и концепции / Под ред. Е.Б. Старовойтенко, В.Д. Шадрикова. М.: НОУ ВПО МПСИ, 2009б.

Штерн В. Дифференциальная психология и ее методические основы. М.: Наука, 1998. 